\title{
First example of stepwise, zwitterionic mechanism for bicyclo[2.2.1]hept-5-ene (norbornene) formation process catalyzed by the 1-butyl-3-methylimidazolium cations
}

\author{
Radomir Jasiński ${ }^{1}$
}

Received: 30 December 2015/Accepted: 9 March 2016/Published online: 30 March 2016

(c) The Author(s) 2016. This article is published with open access at Springerlink.com

\begin{abstract}
B3LYP/6-31++G(d) calculations indicated that the reaction of (2E)-3-phenyl-2-nitroprop-2-enenitrile with cyclopentadiene catalyzed by cations of 1,3-dialkylimidazolium ionic liquid shall not take place according to the classical scheme of one-step [2+4] DielsAlder cycloaddition. Along the path finally leading to bicyclo[2.2.1] hept-5-ene (norbornene) with a nitro group in endo orientation, the process of bicarbocyclic skeleton formation shall take place according to the domino mechanism, via $[2+4]$ heterocycloadduct. On the other hand, along the path leading finally to bicyclo[2.2.1]hept-5ene with a nitro group in exo orientation, acyclic adduct with a zwitterionic nature is formed in the first reaction, which undergoes cyclisation next in the second step of the reaction.
\end{abstract}

Graphical abstract

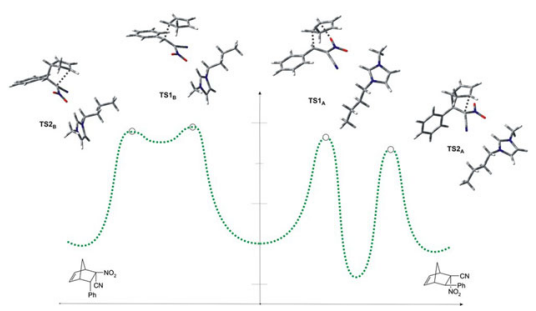

Keywords Diels-Alder reaction · Nitroalkenes . Mechanism · DFT study

Radomir Jasiński

radomir@chemia.pk.edu.pl

1 Institute of Organic Chemistry and Technology, Cracow University of Technology, Cracow, Poland

\section{Introduction}

The Diels-Alder reaction (DA) is generally the most universal synthesis method of bicyclic carbon skeletons [1-3]. In particular, using cyclopentadiene $(\mathrm{Cp})$ and ethylene derivatives, it is possible to synthesize a wide range of compounds from the bicyclo[2.2.1]hept-5-ene (norbornene) group. In general, it is accepted that DA reactions take place according to a one-step mechanism $[1,4,5]$. However, it has been shown recently [6-8] that in case of components with a high electrophilic and nucleophilic activation, the one-step mechanism may compete with a two-step, zwitterionic mechanism.

This work is a continuation of systematic studies on mechanistic aspects of DA involving conjugated nitroalkenes [9-14]. It was shown previously [11, 12], that DA occurring between (2E)-3-aryl-2-nitroprop-2-enenitriles 1a-1f and Cp (2) take place under mild conditions and lead, with high yields, to mixtures of expected, stereoisomeric, nitrosubstituted bicyclo[2.2.1] hept-5-enes (Scheme 1). It should be noted also, that under similar conditions described recently, DA proceeds between the same nitroalkenes and 2,3-dimethyl-1,3-butadiene [15].

In addition, detailed quantum-chemical studies showed [13] that DA 1a-1f $+\mathbf{2}$ take place according to a polar [16] one-step mechanism. The polar nature of these processes was also confirmed using kinetic tests [14]. Taking into account the strongly asynchronous and polar nature of transition states (TSs) of these reactions, it can be assumed that in presence of ionic liquids, it could be possible to force a twostep, zwitterionic mechanism of bicyclo[2.2.1]hept-5-ene rings creation(Scheme 2). This mechanism would be facilitated by (a) the effect of nitroalkene complexation by the cation of the ionic liquid (which should increase the global electrophilicity of the ethylene derivative [17] and stimulate 
Scheme 1

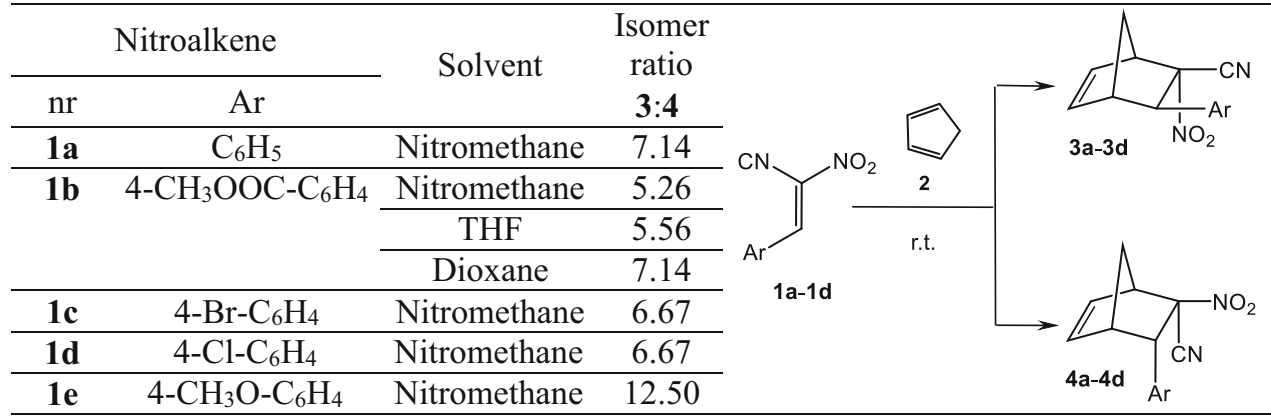

delocalisation of the charges developed along the reaction) and additionally by (b) a polar environment. This type of radical change of the reaction mechanism determined by the presence of 1,3-dialkylimidazolium cations of ionic liquids is suggested in recent works on 1,3-dipolar cycloaddition of (Z)-C-methoxyphenyl- $N$-phenylnitrone to 1-chloro-1-nitroethene [18]. It should be noted that no cases of stepwise DA reactions catalyzed by ionic liquids have been presented in the literature.

Taking the above into account, within this work, DFT simulations were performed for competitive paths of the model reaction between nitroalkene 1a linked by 1-butyl-3-methylimidazolium cation (BMIM) (currently popular and widely present in various ionic liquids used as media for cycloaddition reactions $[19,20])$ and $C p$ (2). These calculations should help with understanding the role of ionic liquids in the medium of polar DA reactions.

\section{Results and discussion}

As the DFT calculations showed, formation of a prereaction complex between nitroalkene $1 \mathbf{a}$ and the BMIM cation results in lowering the enthalpy of the system by $4 \mathrm{~kJ} / \mathrm{mol}$. The formed structure has a strongly electrophilic nature: using the Domingo scale [17], complex [1a + BMIM] should be treated as a strong electrophile. The global electrophilicity of $[1 \mathbf{a}+$ BMIM] exceeds $3.8 \mathrm{eV}$ and is higher than that of highly reactive nitroalkenes such as 1,1-dinitroethene or 2-nitroprop-1-ene (see Table 1). On the other hand, $\mathrm{Cp}$ has a very weak electrophilic nature and in its reaction with [1a + BMIM] it will act as a strong nucleophile [21] $(N>3 \mathrm{eV})$. The high electrophilic character of complex $[1 \mathrm{a}+\mathrm{BMIM}]$ together with the strong nucleophilic character of $\mathrm{Cp}$ is significant, which indicates the analyzed process should be classified as a clearly polar reaction.

The more kinetically favorable reaction path is path A, eventually leading to bicyclo[2.2.1]hept-5-ene with nitro group in endo orientation. In the first step of this reaction, interactions between [1a + BMIM] and 2 lead to $\mathrm{TS} 1_{\mathrm{A}}$ (Table 2; Figs. 1, 2). It results in an enthalpy increase of over $55 \mathrm{~kJ} / \mathrm{mol}$. This barrier, however, is significantly smaller than shown by DFT calculations for a similar reaction taking place without dialkylimidazolium cations [13]. Thus, the effect of nitroalkene complexation by the ionic liquid actually increases its reactivity. The increase in enthalpy is accompanied by strong entropy reduction, which is typical for highly ordered structures.

A C-C single bond between $\mathrm{C} 4$ and $\mathrm{C} 5$ atoms is formed after to pass $\mathrm{TS}_{\mathrm{A}}$. The bond between $\mathrm{C} 1$ and $\mathrm{C} 6$ atoms (which exists in the final bicyclo[2.2.1]hept-5-ene skeleton) is not formed during this step. Instead, a bond between the $\mathrm{C} 3$ atom introduced from $\mathrm{Cp}$ and the oxygen atom of the nitro group is formed (Table 3; Fig. 2). It should be noted that the progression of new bonds creation is definitely varied $(\Delta \mathrm{l}>0.5)$. The asynchronicity in new bonds formation is accompanied by a strong effect of electron density shift towards the ethylene derivative substructure. This effect is quantitatively represented by the global electron density transfer (GEDT) index (0.68 e). Thus, $\mathrm{TS} 1_{\mathrm{A}}$ is definitively asynchronous and has polar nature. IRC calculations relate $\mathrm{TS} 1_{\mathrm{A}}$ to the addents valley (on one hand) and to the intermediate valley on the other. A detailed analysis of IRC trajectories showed that this process should be included (according to terminology by Domingo [25]) to the "one-step two stage cycloaddition" group.

Conversion of the reacting system from $\mathrm{TS}_{\mathrm{A}}$ along the reaction coordinate leads to creation of the intermediate. However, this is not the expected zwitterion $\mathrm{I}_{\mathrm{A}}$, but a nitronic ester 5a. Its transformation into nitrosubstituted bicyclo[2.2.1]hept-5-ene 3a takes place via $\mathrm{TS} 2_{\mathrm{A}}$. Within $\mathrm{TS} 2_{\mathrm{A}}$, the bond $\mathrm{C} 3-\mathrm{O} 7$ is ruptured, and subsequently the $\mathrm{C} 6-\mathrm{C} 1$ bond is formed. Electron density redistribution takes place within the six-membered cyclic system, with the bond between the C6 atom and the nitrogen atom introduced by the nitro group losing its double bond nature. 
Table 1 Global electronic properties of reaction components as well as selected conjugated nitroalkenes $[13$, 22-24]

\begin{tabular}{lllll}
\hline & $\mu / \mathrm{eV}$ & $\eta / \mathrm{eV}$ & $\omega / \mathrm{eV}$ & $N / \mathrm{eV}$ \\
\hline $\mathbf{2}$ & -3.01 & 5.49 & 0.83 & 3.36 \\
$\mathbf{1 a}$ & -5.28 & 4.07 & 3.42 & 1.81 \\
{$[\mathbf{1 a}+$ BMIM] } & -5.44 & 3.83 & 3.87 & 1.76 \\
1,1-Dinitroethene & -5.98 & 5.03 & 3.56 & 0.62 \\
2-Nitroprop-1-ene & -5.16 & 5.48 & 2.43 & 1.22 \\
(E)-3,3,3-Trichloro-1-nitroprop-1-ene & -5.93 & 5.13 & 3.43 & 0.66 \\
\hline
\end{tabular}

Table 2 Kinetic and thermodynamic parameters for reactions between $(2 E)-3$ phenyl-2-nitroprop-2-enenitrile (1a) and $\mathrm{Cp}$ (2) catalyzed by the 1-butyl-3-methylimidazolium ionic liquid cations according to B3LYP/6-

$31++\mathrm{G}(\mathrm{d})$ calculations

\begin{tabular}{llrl}
\hline Path & Transition & $\Delta H / \mathrm{kJ} \mathrm{mol}^{-1}$ & $\Delta S / \mathrm{J} \mathrm{mol}^{-1} \mathrm{~K}^{-1}$ \\
\hline \multirow{2}{*}{$\mathbf{1 a}+\mathrm{BMIM} \rightarrow[\mathbf{1 a} / \mathrm{BMIM}]$} & -3.99 & -123.77 \\
& {$[\mathbf{1 a} / \mathrm{BMIM}]+\mathbf{2} \rightarrow \mathrm{TS} 1_{\mathrm{A}}$} & 55.14 & -208.87 \\
& {$[\mathbf{1 a} / \mathrm{BMIM}]+\mathbf{2} \rightarrow[\mathbf{5 a} / \mathrm{BMIM}]$} & -18.52 & -216.61 \\
& {$[\mathbf{1 a} / \mathrm{BMIM}]+\mathbf{2} \rightarrow \mathrm{TS} 2_{\mathrm{A}}$} & 51.01 & -225.27 \\
& {$[\mathbf{1 a} / \mathrm{BMIM}]+\mathbf{2} \rightarrow[\mathbf{3 a} / \mathrm{BMIM}]$} & -5.05 & -249.74 \\
$\mathrm{~B}$ & {$[\mathbf{1} / \mathrm{BMIM}]+\mathbf{2} \rightarrow \mathrm{TS} 1_{\mathrm{B}}$} & 61.08 & -188.79 \\
& {$[\mathbf{1 a} / \mathrm{BMIM}]+\mathbf{2} \rightarrow\left[\mathrm{I}_{\mathrm{B}} / \mathrm{BMIM}\right]$} & 52.86 & -228.35 \\
& {$[\mathbf{1 a} / \mathrm{BMIM}]+\mathbf{2} \rightarrow \mathrm{TS} 2_{\mathrm{B}}$} & 56.02 & -219.77 \\
& {$[\mathbf{1 a} / \mathrm{BMIM}]+\mathbf{2} \rightarrow[\mathbf{4 a} / \mathrm{BMIM}]$} & -1.44 & -209.36 \\
\hline
\end{tabular}

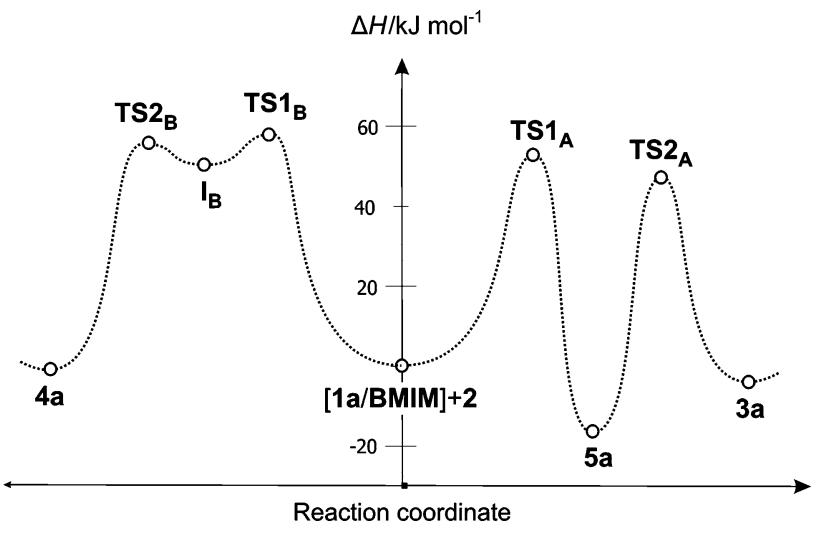

Fig. 1 Enthalpy profiles for reactions between (2E)-3-phenyl-2nitroprop-2-enenitrile (1a) and Cp (2) catalyzed by the 1-butyl-3methylimidazolium ionic liquid cations according to B3LYP/6$31++\mathrm{G}(\mathrm{d})$ calculations

This is accompanied by migration of the double bond within the five-membered ring. Formally, the analyzed process should be interpreted as a [3.3]-sigmatropic rearrangement. Similar rearrangements of other internal nitronic esters have been recently described [26-28].

In sum, the nature of transformations occurring during substrate conversion into endo-nitro bicyclo[2.2.1]hept-5ene 3a can be illustrated similarly to Scheme 3 . As can be seen, instead of a typical DA reaction, the presented case is a "domino" type process, taking place via a hetero-DielsAlder reaction, followed by a sigmatropic rearrangement.
The less favorable, although not forbidden from the kinetic point of view, is path $\mathrm{B}$, eventually leading to bicyclo[2.2.1] hept-5-ene with its nitro group in exo orientation. In this reaction, interactions between [1a + BMIM] and 2 lead to $\mathrm{TS}_{\mathrm{B}}$ (Table 2; Figs. 1,2). This results in an enthalpy increase by $61.08 \mathrm{~kJ} / \mathrm{mol}$. Within $\mathrm{TS} 1_{\mathrm{B}}$ only one new bond is formed, namely the bond between $\mathrm{C} 4$ and $\mathrm{C} 5$ atoms. The distance between $\mathrm{C} 1$ and $\mathrm{C} 6$ atoms at this reaction stage remains outside the range typical for $\mathrm{C}-\mathrm{C}$ bonds in TSs. IRC calculations relate $\mathrm{TS} 1_{\mathrm{B}}$ to the addent valley (on one hand) and to the intermediate valley on the other. This intermediate is the expected (Scheme 2) acyclic adduct $\mathrm{I}_{\mathrm{B}}$. Its reoptimization using UB3LYP/6$31 \mathrm{G}++(\mathrm{d})$ theory level excluded diradical nature ( $(\mathrm{S} 2\rangle$ value is equal 0.00). At the same time, its zwitterionic nature is confirmed by the value of the GEDT index $\left(0.95\right.$ e). $I_{B}$ is not-under reaction conditions-a thermodynamically stable structure and easily undergoes conversion to the final product. This process takes place via $\mathrm{TS} 2_{\mathrm{B}}$. Within $\mathrm{TS} 2_{\mathrm{B}}$ the second new $\sigma$-bond is formed. In particular, it is the C1-C6 bond (Table 3). Further conversion of the reacting system along the reaction coordinate leads to nitrosubstituted bicyclo[2.2.1]hept-5-ene 4a.

Thus, the nature of transformations occurring during substrate conversion into exo-nitro bicyclo[2.2.1] hept-5ene 4a can be illustrated as shown in Scheme 3. Formally, this process should be interpreted as a stepwise, zwitterionic cycloaddition. 
Path A

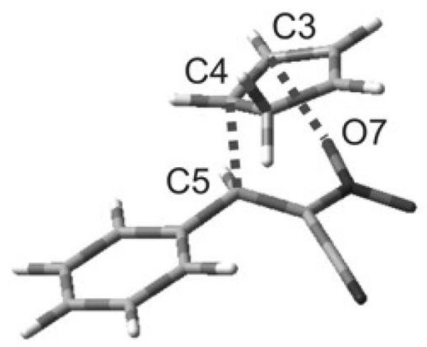

TS1 ${ }_{A}$
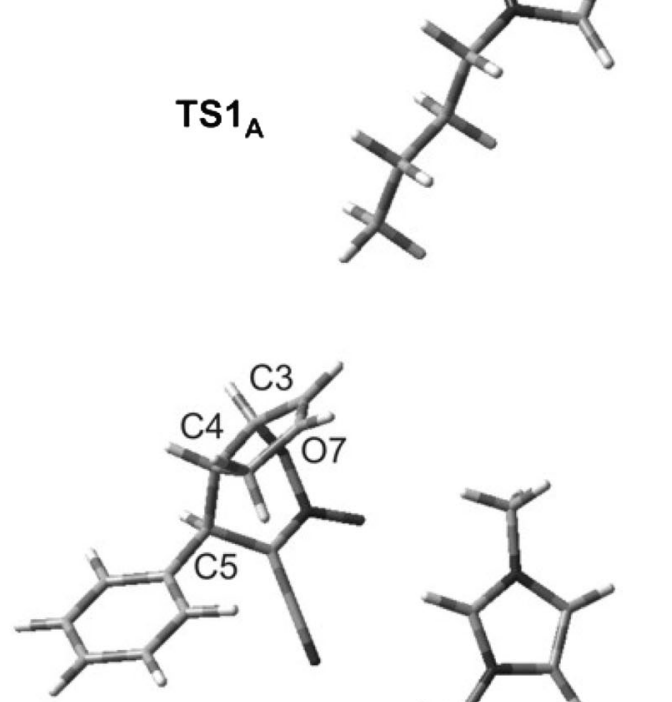

$5 a$
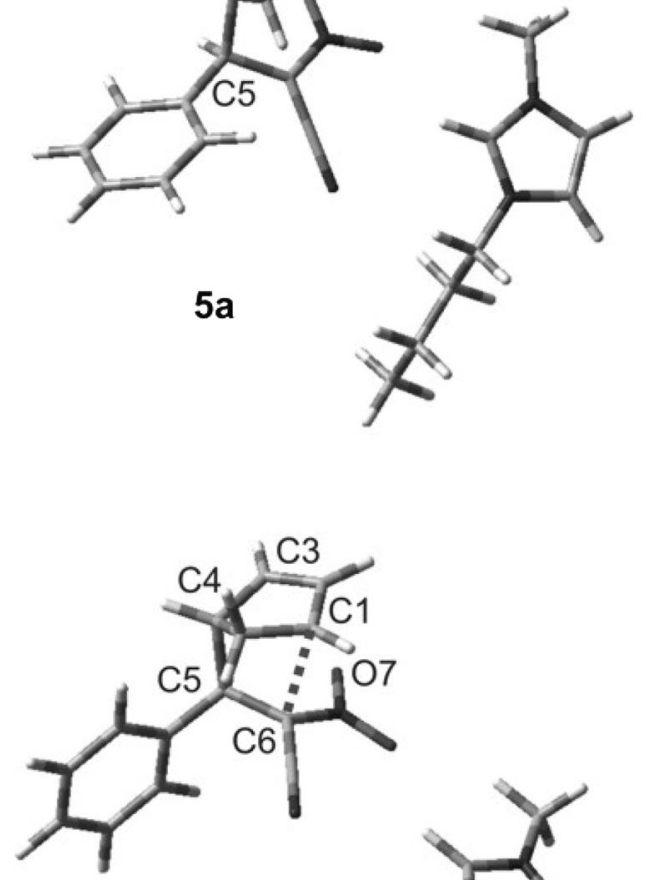

$\mathrm{TS}_{\mathrm{A}}$

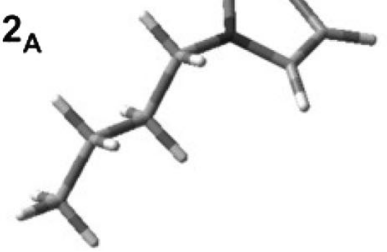

Path B

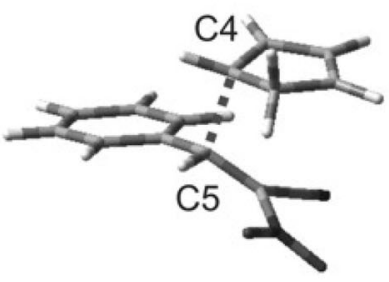

$\mathrm{TS1}_{\mathrm{B}}$
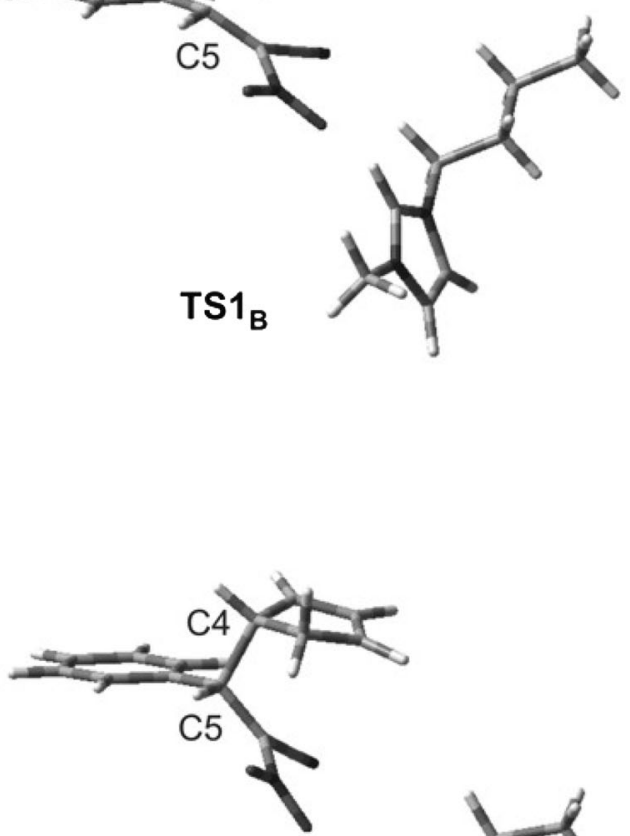

$I_{B}$
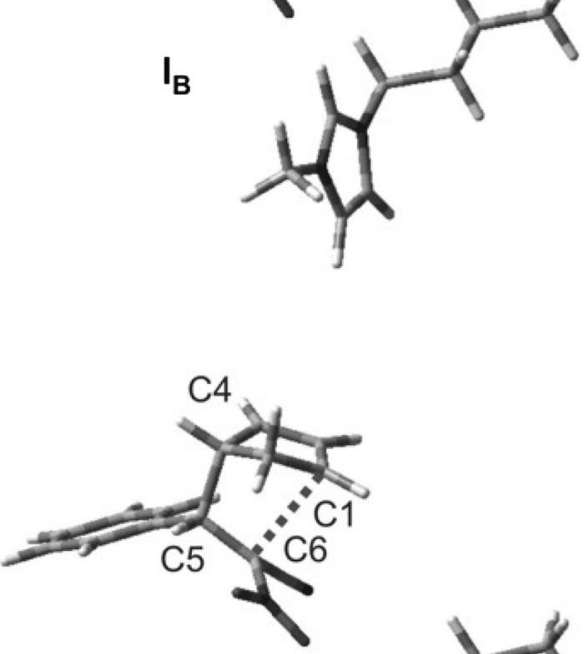

$\mathrm{TS}_{\mathrm{B}}$

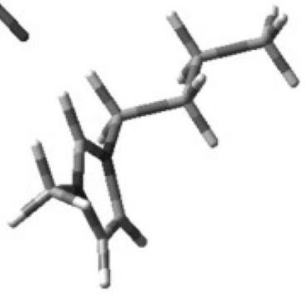

Fig. 2 Key structures of reactions between (2E)-3-phenyl-2-nitroprop-2-enenitrile (1a) and Cp (2) catalyzed by the 1-butyl-3-methylimidazolium ionic liquid cations according to B3LYP/6-31++G(d) calculations 
Table 3 Key parameters for critical structures of reactions between (2E)-3-phenyl-2nitroprop-2-enenitrile (1a) and Cp (2) catalyzed by the 1-butyl3-methylimidazolium ionic liquid cations according to B3LYP/6-

$31++\mathrm{G}(\mathrm{d})$ calculations

\begin{tabular}{|c|c|c|c|c|c|c|c|}
\hline & \multicolumn{2}{|l|}{ C1-C6 } & \multicolumn{2}{|l|}{$\mathrm{C} 4-\mathrm{C} 5$} & \multicolumn{2}{|l|}{$\mathrm{C} 3-\mathrm{O} 7$} & \multirow{2}{*}{$\begin{array}{l}\text { GEDT } \\
\text { /e }\end{array}$} \\
\hline & $r / \AA$ & $1^{\mathrm{a}}$ & $r / \AA$ & $1^{\mathrm{a}}$ & $r / \AA$ & $1^{a}$ & \\
\hline $\mathrm{TS} 1_{\mathrm{A}}$ & 3.237 & & 2.021 & 0.704 & 2.791 & 0.141 & 0.68 \\
\hline [5a/BMIM] & 3.744 & & 1.559 & & 1.501 & & 0.67 \\
\hline $\mathrm{TS} 2_{\mathrm{A}}$ & 2.484 & 0.456 & 1.625 & & 2.966 & & 0.59 \\
\hline [3a/BMIM] & 1.608 & & 1.583 & & 3.395 & & 0.48 \\
\hline $\mathrm{TS} 1_{\mathrm{B}}$ & 3.179 & & 2.010 & 0.793 & & & 0.71 \\
\hline$\left[\mathrm{I}_{\mathrm{B}} / \mathrm{BMIM}\right]$ & 3.130 & & 1.665 & & & & 0.95 \\
\hline $\mathrm{TS} 2_{\mathrm{B}}$ & 2.564 & 0.378 & 1.649 & & & & 0.84 \\
\hline [4a/BMIM] & 1.580 & & 1.605 & & & & 0.77 \\
\hline
\end{tabular}

${ }^{\mathrm{a}} l_{\mathrm{X}-\mathrm{Y}}=1-\frac{r_{\mathrm{X}-\mathrm{Y}}^{\mathrm{TS}}-r_{\mathrm{X}-\mathrm{Y}}^{\mathrm{P}}}{r_{\mathrm{X}}^{\mathrm{P}}}$, where $r_{X-Y}^{\mathrm{TS}}$ is the distance between the reaction centers $\mathrm{X}$ and $\mathrm{Y}$ in the transition structure and $r_{X-Y}^{\mathrm{P}}{ }^{r_{X} \mathrm{Y}}$ iS the same distance in the corresponding product

\section{Scheme 2}

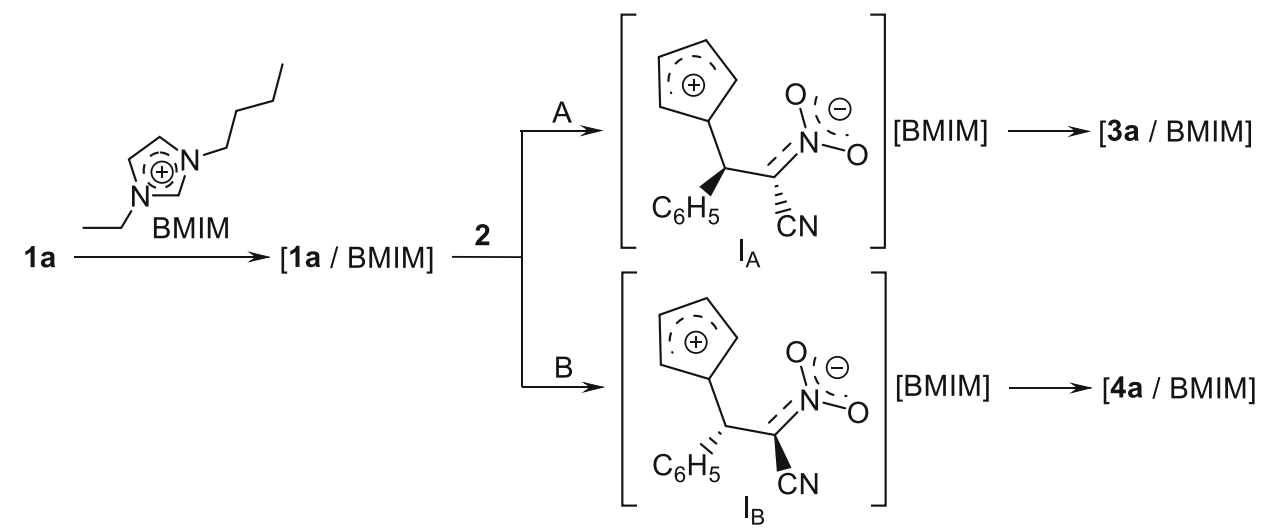

Scheme 3

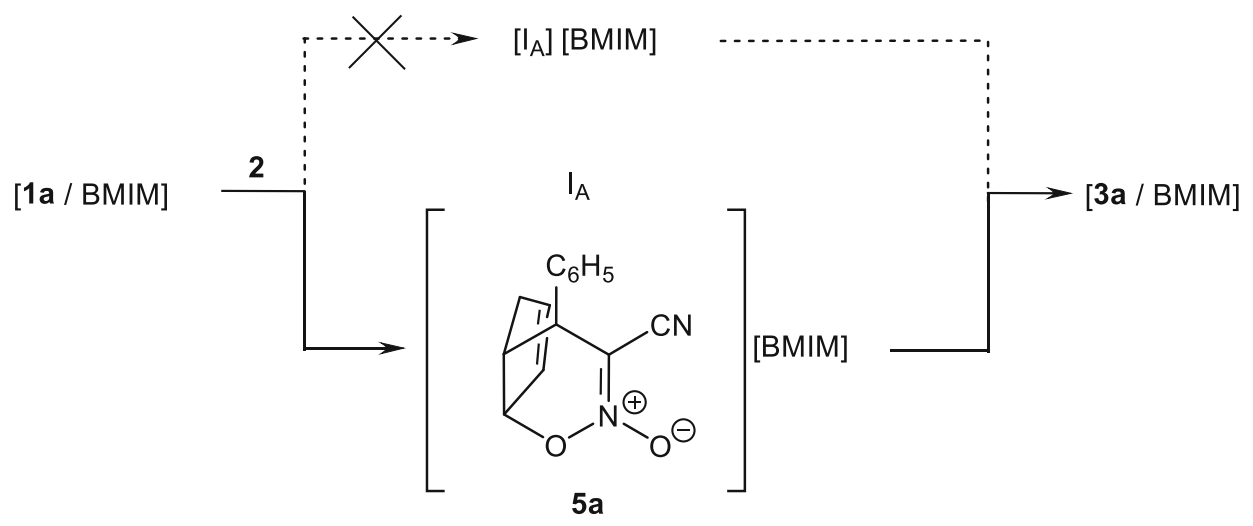




\section{Conclusion}

The reaction of (2E)-3-phenyl-2-nitroprop-2-enenitrile takes place under mild conditions, along two competitive paths eventually leading to stereoisomeric endo- and exonitro bicyclo[2.2.1]hept-5-enes. It may seem that this process takes place according to the simple, well-known DA mechanism. However, as the DFT calculations suggest, in the presence of 1,3-dialkylimidazolium cations of ionic liquids this process should take place much faster, but first and foremost, according to another, more complex mechanism. In particular, the bicyclo[2.2.1]hept-5-ene skeleton formation takes place via a discrete, zwitterionic intermediate along the path eventually leading to exo-nitro bicyclo[2.2.1]hept-5-ene. This is the first case for which a zwitterionic mechanism is postulated for a DA reaction catalyzed by 1,3-dialkylimidazolium cations of ionic liquids.

\section{Computational methods}

All calculations reported in this paper were performed on "Zeus" supercomputer in the "Cyfronet" computational center in Cracow. Hybrid functional B3LYP [29] with the $6-31++\mathrm{G}(\mathrm{d})$, basis set included in the GAUSSIAN 09 package [30] was used. For structure optimization of the reactants, intermediates and the reaction products the Berny algorithm was applied. First-order saddle points were localized using the QST2 [31] procedure. The TSs were verified by diagonalization of the Hessian matrix and by analysis of the intrinsic reaction coordinates (IRC) [32]. For optimized structures the thermochemical data for the temperature $T=298 \mathrm{~K}$ and pressure $p=1 \mathrm{~atm}$ were computed using vibrational analysis data. The reaction environment polarity was simulated using PCM [33]. This model has been used previously for successful diagnosis of several aspects of DA reactions involving nitroalkenes [9, $10,13]$. It was assumed that the reaction environment has dielectric constant, $\varepsilon=13.0$, because most typical 1-butyl3-methylimidazolium ionic liquids have $\varepsilon \approx 12-15$ [34]. Similar approach has been successfully used by the Domingo group for the analysis of Diels-Alder reaction between $N$-tosylpyrroles and isoprene in the presence of dialkylimidazolium ionic liquids [35]. Global electron density transfer (GEDT) between substructures [36] was calculated according to the formula:

GEDT $=\Sigma q_{\mathrm{A}}$

where $q_{\mathrm{A}}$ is the net charge and the sum is taken over all the atoms of $\mathrm{Cp}$.

Global electronic properties of reactants were estimated according to the equations recommended by Parr and Domingo [17, 37] using (according to Domingo suggestions $[17,36])$ B3LYP/6-31G(d) theoretical level. In particular, the electronic chemical potentials $(\mu)$ and chemical hardness $(\eta)$ were evaluated in terms of oneelectron energies of FMO ( $E_{\mathrm{HOMO}}$ and $\left.E_{\mathrm{LUMO}}\right)$ using the following equations:

$\mu \approx\left(E_{\mathrm{HOMO}}+E_{\mathrm{LUMO}}\right) / 2$ and $\eta \approx E_{\mathrm{LUMO}}-E_{\mathrm{HOMO}}$

Next, the values of $\mu$ and $\eta$ were then used for the calculation of global electrophilicity $(\omega)$ according to the formula:

$\omega=\mu^{2} / 2 \eta$

Acknowledgements The generous allocation of computing time by the regional computer center "Cyfronet" in Cracow (Grant No. MNiSW/Zeus_lokalnie/PK/009/2013), and financial support from the Polish State Committee (Grant No. C-2/33/2014/DS) are gratefully acknowledged.

Open Access This article is distributed under the terms of the Creative Commons Attribution 4.0 International License (http:// creativecommons.org/licenses/by/4.0/), which permits unrestricted use, distribution, and reproduction in any medium, provided you give appropriate credit to the original author(s) and the source, provide a link to the Creative Commons license, and indicate if changes were made.

\section{References}

1. Fringuelli F, Taticchi A (2002) Diels-Alder reaction. Selected practical methods. Wiley, New York

2. Nicolaou KC, Snyder SA, Montagnon T, Vassilikogiannakis G (2002) Angew Chem Int Ed 41:1668

3. Moulay S, Touati A (2010) C R Chimie 13:1474

4. Polevaya IS, Makitra GG, Marshalok GA, Kovalskyi YP (2012) Russ J Gen Chem 82:1970

5. Diau EWG, De-Feyter S, Zewail AH (1999) Chem Phys Lett 304:134

6. Korotayev VYu, Barkov AYu, Slepukhin PA, Kodess MI, Sosnovskikh VYa (2011) Mendeleev Commun 21:112

7. Lakhdar S, Terrier F, Vichard D, Berionni G, El-Guesmi N, Goumont R, Boubaker T (2010) Chem Eur J 16:5681

8. Erdn M, Heuschmann M, Zipse H (2005) Helv Chim Acta 88:1491

9. Jasiński R, Kubik M, Łapczuk-Krygier A, Kacka A, Dresler E, Boguszewska-Czubara A (2014) React Kinet Mech Catal 113:333

10. Jasiński R (2014) Comput Theor Chem 1046:93

11. Łapczuk-Krygier A, Ponikiewski P, Jasiński R (2014) Crystallogr Rep 59:961

12. Jasiński R, Rzyman M, Barański A (2010) Coll Czech Chem Commun 75:919

13. Jasiński R, Barański A (2010) J Mol Struct (Theochem) 949:8

14. Jasiński R, Kwiatkowska M, Barański A (2012) Monatsh Chem 143:895

15. Baichurin RI, Aboskalova NI, Trukhin EV, Berestovitskaya VM (2015) Russ J Gen Chem 85:1845

16. Domingo LR, Saez JA (2009) Org Biomol Chem 7:3576

17. Domingo LR, Aurell MJ, Pérez P, Contreras R (2002) Tetrahedron 58:4417

18. Jasiński R (2015) Tetrahedron Lett 56:532 
19. Dresler E, Jasińska E, Łapczuk-Krygier A, Nowakowska-Bogdan E, Jasiński R (2015) Chemik 69:288

20. Vidiš A, Küsters E, Sedelmeier G, Dyson PJ (2007) J Phys Org Chem 21:264

21. Jaramillo P, Domingo LR, Chamorro E, Pérez P (2008) J Mol Struct (Theochem) 865:68

22. Jasiński R (2013) Tetrahedron 69:927

23. Jasiński R (2015) J Heterocycl Chem 52:185

24. Jasiński R, Ziółkowska M, Demchuk OM, Maziarka A (2014) Central Eur J Chem 12:586

25. Domingo LR, Saéz JA, Zaragozá RJ, Arno M (2008) J Org Chem 73:8791

26. Wade PA, Pipic A, Zeller M, Tsetsakos P, Beilstein (2013) J Org Chem 9:2137

27. Arroyo P, Picher MT, Domingo LR, Terrier F (2005) Tetrahedron 61:7359

28. Jasiński R, Barański A (2011) Central Eur J Chem 9:1008

29. Becke AD (1993) J Chem Phys 98:5648

30. Frisch MJ, Trucks GW, Schlegel HB, Scuseria GE, Robb MA, Cheeseman JR, Scalmani G, Barone V, Mennucci B, Petersson GA, Nakatsuji H, Caricato M, Li X, Hratchian HP, Izmaylov AF, Bloino J, Zheng G, Sonnenberg JL, Hada M, Ehara M, Toyota K, Fukuda R, Hasegawa J, Ishida M, Nakajima T, Honda Y, Kitao
O, Nakai H, Vreven T, Montgomery JA, Peralta JE, Ogliaro F, Bearpark M, Heyd JJ, Brothers E, Kudin KN, Staroverov VN, Kobayashi R, Normand J, Raghavachari K, Rendell A, Burant JC, Iyengar SS, Tomasi J, Cossi M, Rega N, Millam NJ, Klene M, Knox JE, Cross JB, Bakken V, Adamo C, Jaramillo J, Gomperts R, Stratmann RE, Yazyev O, Austin AJ, Cammi R, Pomelli C, Ochterski JW, Martin RL, Morokuma K, Zakrzewski VG, Voth GA, Salvador P, Dannenberg JJ, Dapprich S, Daniels AD, Farkas O, Foresman JB, Ortiz JV, Cioslowski J, Fox DJ (2009) Gaussian 09, Revision A.01. Gaussian, Inc, Wallingford, CT

31. Peng C, Ayala PY, Schlegel HB, Frisch MJ (1996) J Comp Chem 17:49

32. Hratchian HP, Schlegel HB (2005) J Chem Theor Comput 1:61

33. Cossi M, Rega N, Scalmani G, Barone V (2003) J Comp Chem 24:669

34. Huang MM, Jiang Y, Sasisanker P, Driver GW, Weingärtner H (2011) J Chem Eng Data 5:1494

35. Mancini PM, Ormachea CM, Della Rosa CD, Kneeteman MN, Suarez AG, Domingo LR (2012) Tetrahedron Lett 53:6508

36. Domingo LR (2014) RSC Adv 4:32415

37. Parr RG, von Szentpaly L, Liu LS (1999) J Am Chem Soc 121:1922 